http://jmscr.igmpublication.org/home/ ISSN (e)-2347-176x ISSN (p) 2455-0450

crossref DOI: https://dx.doi.org/10.18535/jmscr/v8i1.29

\author{
Journal Of Medical Science And Clinical Research \\ IGM Publication \\ An official Publication of IGM Publication
}

\title{
Inter and Intra-Hemispheric Resting EEG Coherence in Schizophrenia Patients
}

\section{Authors \\ Patel Bhoopendra ${ }^{1}$, Kumawat Ashok Kumar ${ }^{2 *}$, Gupta Kapil ${ }^{3}$, Mathur Kapil Dev ${ }^{4}$, Tak Amit ${ }^{5}$}

${ }^{1}$ Assistant Professor, Department of Physiology, Government Medical College, Barmer (Rajasthan)

${ }^{2}$ Senior Professor, Department of Physiology, S. M. S. Medical College, Jaipur (Rajasthan)

${ }^{3}$ Associate Professor, Department of Physiology, S. M. S. Medical College, Jaipur (Rajasthan)

${ }^{4}$ Senior Medical Officer, J. L. N. Medical College, Ajmer

${ }^{5}$ Senior Resident, Department of Physiology, S. M. S. Medical College, Jaipur (Rajasthan)

*Corresponding Author

\section{Ashok Kumar Kumawat}

Senior Professor, Department of Physiology, S. M. S. Medical College, Jaipur (Rajasthan)

\begin{abstract}
Schizophrenia is a chronic and disabling mental disorder characterized by distortions in thinking, perception, emotions, language, sense of self and behaviour. The oscillatory pattern of electrical activity generated by synchronized neuronal firing at rest might help in identifying the subjects of schizophrenia. Though various studies have tried to assess the underlying functional connectivity and its impairment in the patients of schizophrenia, the exact mechanism remains to be elucidated. The present study was conducted in the Department of Physiology in collaboration with the Department of Psychiatry, S. M. S. Medical College, Jaipur (Rajasthan). Twenty-one newly diagnosed schizophrenia patients aged 18-40 years from Psychiatry $O P D$ were recruited as cases and an equal no. of age matched healthy subjects were recruited as controls from the accompanying attendants of patients. The inter and intra-hemispheric coherence among various brain areas was evaluated in delta, theta, alpha 1, alpha 2, beta 1, beta 2and gamma frequency bands. The resting EEG coherence was significantly reduced between various electrode pairs in schizophrenia patients in delta (C3-P3, P3-T3, F3-P3\&P3-P4), theta (C3-P3, P3-T3, F3-P3\&P3-P4), alpha-1(C3-P3, P3-T3\& C4T4), alpha-2 (C3-P3, P3-T3\&C4-T4) and gamma (C3-P3\& P3-P4) frequency bands as compared to healthy controls. The schizophrenia patients exhibit functional dysconnectivity in frontal, central, parietal and temporal regions that might underlie the impaired thought process in schizophrenia patients, especially in the left hemisphere.

Keywords: Schizophrenia, Electroencephalogram (EEG), Coherence, Functional Connectivity, Interhemispheric and Intra-hemispheric.
\end{abstract}

\section{Introduction}

Schizophrenia is a chronic and disabling mental disorder characterized by distortions in thinking, perception, emotions, language, sense of self and behavior. Schizophrenia has been reported to affect about $1 \%$ of the population, with a considerable impact on the psychosocial functioning and quality of life ${ }^{[1],[2]}$. The unaffected siblings of schizophrenia 
patients have also shown to exhibit cognitive and developmental abnormalities, suggesting a possible combination of genetic and environmental risk factors causing aberrant pattern of neuronal communications $^{[3],[4]}$.

Neural oscillations are the basis of functional connectivity among different brain areas. Defect in neural oscillations and synchronization has been implicated in the recent available literature as a pathophysiological mechanism in schizophrenia patients. This is also evident from the neuroimaging-based studies in schizophrenia patients $^{[5]-[8]}$. However, the available literature reports mixed findings, with both increased and decreased functional connectivity in resting conditions $^{[9]-[12]}$.

\section{Resting EEG Coherence}

The oscillatory pattern of electrical activity generated by synchronized neuronal firing at rest might help in identifying the subjects of schizophrenia $^{[13],[14]}$. Modalities like magneto encephalogram (MEG) and electroencephalogram (EEG) have made it possible to quantify the electrophysiological processes occurring among various neuronal pools, using network connectivity analysis. EEG technique has a good temporal resolution that provides an efficient way for exploring functional and effective connectivity between two distinct brain regions using coherence and phase synchrony. EEG coherence (range from 0 to 1) evaluates the consistency of relative amplitude and phase between signals detected in different brain areas within a specific frequency band. A consistent similarity in rise and fall of phase between two signals over the time, at different brain areas, within a specific frequency band suggests functional connectivity ${ }^{[15]}$.

The psychotic disorders have underlying impaired thought process $^{[16]-[19]}$ and impaired autobiographical memory retrieval ${ }^{[19],[20]}$. These processes involve default mode network (DMN), ${ }^{[21]-[23]}$ that are more active at rest than during task performance ${ }^{[24],[25]}$. The components of DMN are areas like precuneus, posterior cingulate cortex, medial prefrontal cortex and temporo-parietal junction $^{[26,27]}$.

Though various studies have tried to assess the underlying functional connectivity and its impairment in the patients of schizophrenia, the exact mechanism still remains to be elucidated ${ }^{[28]-}$ [30]. Most of the available literature on functional connectivity in schizophrenics did not take all the frequency bands into account for evaluation of EEG coherence. Thus, this study was an attempt to decipher the deranged functional neuronal connectivity in schizophrenia patients in terms of coherence across all frequency bands.

\section{Material and Methods}

The present study was conducted in the Department of Physiology in collaboration with the Department of Psychiatry, S. M. S. Medical College, Jaipur (Rajasthan). Twenty-one newly diagnosed schizophrenia patients, aged 18-40 years, according to the criteria of Diagnostic and Statistical

Manual of Mental Disorders, 4th Edition (DSM-IV TR, 2000) attending OPD of the Department of Psychiatry, S M. S. Medical College, Jaipur were recruited as cases and an equal no. of age matched healthy subjects were recruited as controls from the accompanying attendants of patients. A prior clearance from institutional ethical committee was obtained and a written, informed consent was obtained from every subject before commencing any procedure.

\section{EEG acquisition}

All the subjects were instructed a day before to come for recording with their hairs washed and no oil applied on scalp. The procedure was explained in detail to every subject and recording was done in a sound attenuated room with dim light in sitting position on a wooden chair. 21 channel scalp electroencephalography was done according to International 10-20 system for EEG electrode placement $^{[31]}$.

Electrode impedance was kept below $5 \mathrm{k} \Omega$ and a band pass filter of $0.5-70.0 \mathrm{~Hz}$, digitalized at sampling rate of $256 \mathrm{~Hz}$ was used. EEG recording 
was done using Brain Electro Scan System (BESS, Axxonet System, Bengaluru) of the EEG was recorded using a stretchable cap and positioned on the subject's head according to the known anatomical landmarks. The EEG recordings were run for 5 minutes with subject at rest during eye closed session. The recorded EEG was visually inspected and edited manually for artefacts free data. The Interhemispheric (F3-F4, C3-C4, T3-T4, P3-P4, O1-O2) and intra-hemispheric (Right: F4C4, F4-P4, C4-P4, F4-T4, C4-T4, P4-T4 and Left: F3-C3, F3-P3, C3-P3, F3-T3, C3-T3, P3-T3) coherence among various brain areas was evaluated in delta $(0.5-4.0 \mathrm{~Hz})$, theta $(4.1-8.0 \mathrm{~Hz})$, alpha 1 (8.1-10.0 Hz), alpha $2(10.1-13 \mathrm{~Hz})$, beta 1 (13.1$20.0 \mathrm{~Hz})$, beta $2(20.1-30 \mathrm{~Hz})$ and gamma frequency bands $(30.1-80 \mathrm{~Hz})$.

\section{Statistical Analysis}

The tabulation and analysis of recorded data was done using Microsoft Excel 2016. The unpaired ttest was used for the mean coherence comparison between schizophrenia and control groups in various frequency bands. The level of statistical significance was assigned at $\mathrm{p}$-value less than 0.05 .

Table 1 Comparison of mean and standard deviation of Left Intra-hemispheric EEG coherence of schizophrenia patients with healthy controls

\begin{tabular}{|c|c|c|c|c|c|c|c|}
\hline \multicolumn{2}{|c|}{ Electrode Pairs } & F3-C3 & C3-P3 & P3-T3 & F3-P3 & F3-T3 & C3-T3 \\
\hline \multirow{2}{*}{$\begin{array}{l}\text { Delta } \\
(0.5-4 \text { Hz) }\end{array}$} & Schizophrenia & $0.569 \pm 0.268$ & $0.306 \pm 0.3^{*}$ & $0.24 \pm 0.215^{*}$ & $0.217 \pm 0.197 *$ & $0.455 \pm 0.222$ & $0.485 \pm 0.236$ \\
\hline & Control & $0.602 \pm 0.276$ & $0.591 \pm 0.258$ & $0.472 \pm 0.198$ & $0.372 \pm 0.215$ & $0.517 \pm 0.215$ & $0.558 \pm 0.217$ \\
\hline \multirow{2}{*}{$\begin{array}{l}\text { Theta } \\
(4.1-8 \text { Hz) }\end{array}$} & Schizophrenia & $0.483 \pm 0.268$ & $0.214 \pm 0.231 *$ & $0.151 \pm 0.169 *$ & $0.122 \pm 0.153^{*}$ & $0.316 \pm 0.244$ & $0.355 \pm 0.262$ \\
\hline & Control & $0.509 \pm 0.268$ & $0.472 \pm 0.241$ & $0.345 \pm 0.186$ & $0.234 \pm 0.181$ & $0.382 \pm 0.208$ & $0.454 \pm 0.2$ \\
\hline \multirow{2}{*}{$\begin{array}{l}\text { Alpha-1 } \\
(8.1-10 \mathrm{~Hz})\end{array}$} & Schizophrenia & $0.45 \pm 0.254$ & $0.171 \pm 0.202 *$ & $0.139 \pm 0.145^{*}$ & $0.147 \pm 0.154$ & $0.277 \pm 0.208$ & $0.31 \pm 0.226$ \\
\hline & Control & $0.475 \pm 0.256$ & $0.353 \pm 0.242$ & $0.279 \pm 0.222$ & $0.169 \pm 0.165$ & $0.323 \pm 0.263$ & $0.429 \pm 0.229$ \\
\hline \multirow{2}{*}{$\begin{array}{l}\text { Alpha-2 } \\
(10.1-13 H z)\end{array}$} & Schizophrenia & $0.356 \pm 0.219$ & $0.159 \pm 0.201 *$ & $0.106 \pm 0.141 *$ & $0.13 \pm 0.15$ & $0.212 \pm 0.189$ & $0.244 \pm 0.191$ \\
\hline & Control & $0.398 \pm 0.234$ & $0.297 \pm 0.21$ & $0.214 \pm 0.173$ & $0.132 \pm 0.116$ & $0.243 \pm 0.219$ & $0.354 \pm 0.213$ \\
\hline \multirow{2}{*}{$\begin{array}{l}\text { Beta-1 } \\
(13.1-20 \mathrm{~Hz})\end{array}$} & Schizophrenia & $0.343 \pm 0.218$ & $0.158 \pm 0.21$ & $0.104 \pm 0.179$ & $0.119 \pm 0.179$ & $0.191 \pm 0.197$ & $0.214 \pm 0.212$ \\
\hline & Control & $0.359 \pm 0.243$ & $0.281 \pm 0.234$ & $0.135 \pm 0.154$ & $0.111 \pm 0.143$ & $0.169 \pm 0.192$ & $0.202 \pm 0.16$ \\
\hline \multirow{2}{*}{$\begin{array}{l}\text { Beta-2 } \\
(20.1-30 \mathrm{~Hz})\end{array}$} & Schizophrenia & $0.268 \pm 0.182$ & $0.121 \pm 0.166$ & $0.078 \pm 0.125$ & $0.089 \pm 0.116$ & $0.147 \pm 0.149$ & $0.182 \pm 0.168$ \\
\hline & Control & $0.269 \pm 0.221$ & $0.225 \pm 0.214$ & $0.089 \pm 0.109$ & $0.09 \pm 0.151$ & $0.119 \pm 0.14$ & $0.132 \pm 0.108$ \\
\hline \multirow{2}{*}{$\begin{array}{l}\text { Gamma } \\
(30.1-50 ~ H z)\end{array}$} & Schizophrenia & $0.25 \pm 0.172$ & $0.109 \pm 0.109 *$ & $0.072 \pm 0.06$ & $0.081 \pm 0.063$ & $0.176 \pm 0.139$ & $0.185 \pm 0.145$ \\
\hline & Control & $0.217 \pm 0.18$ & $0.233 \pm 0.189$ & $0.099 \pm 0.082$ & $0.129 \pm 0.136$ & $0.116 \pm 0.1$ & $0.124 \pm 0.096$ \\
\hline
\end{tabular}

*Significant (p-value <0.05)

Table 2 Comparison of mean and standard deviation of Right intra-hemispheric EEG coherence of schizophrenia patients with healthy controls

\begin{tabular}{|c|c|c|c|c|c|c|c|}
\hline \multicolumn{2}{|c|}{ Electrode Pairs } & F4-C4 & C4-P4 & P4-T4 & F4-P4 & F4-T4 & C4-T4 \\
\hline \multirow{2}{*}{$\begin{array}{l}\text { Delta } \\
(0.5-4 \text { Hz) }\end{array}$} & Schizophrenia & $0.263 \pm 0.288$ & $0.458 \pm 0.33$ & $0.447 \pm 0.246$ & $0.204 \pm 0.24$ & $0.259 \pm 0.248$ & $0.445 \pm 0.288$ \\
\hline & Control & $0.245 \pm 0.312$ & $0.514 \pm 0.333$ & $0.451 \pm 0.204$ & $0.16 \pm 0.176$ & $0.254 \pm 0.252$ & $0.561 \pm 0.286$ \\
\hline \multirow{2}{*}{$\begin{array}{l}\text { Theta } \\
(4.1-8 \text { Hz) }\end{array}$} & Schizophrenia & $0.215 \pm 0.276$ & $0.344 \pm 0.285$ & $0.303 \pm 0.239$ & $0.134 \pm 0.212$ & $0.164 \pm 0.229$ & $0.292 \pm 0.244$ \\
\hline & Control & $0.225 \pm 0.266$ & $0.411 \pm 0.291$ & $0.335 \pm 0.186$ & $0.138 \pm 0.169$ & $0.201 \pm 0.203$ & $0.418 \pm 0.223$ \\
\hline \multirow{2}{*}{$\begin{array}{l}\text { Alpha-1 } \\
(8.1-10 \mathrm{~Hz})\end{array}$} & Schizophrenia & $0.222 \pm 0.262$ & $0.273 \pm 0.264$ & $0.273 \pm 0.21$ & $0.098 \pm 0.119$ & $0.125 \pm 0.157$ & $0.253 \pm 0.233 *$ \\
\hline & & $0.208 \pm 0.2$ & $0.346 \pm 0.2$ & $309 \pm$ & $0.078 \pm$ & $0.148 \pm 0$ & $0.42 \pm$ \\
\hline \multirow{2}{*}{$\begin{array}{l}\text { Alpha-2 } \\
(10.1-13 \text { Hz) }\end{array}$} & Schizo & $159 \pm 0$ & $0.251 \pm 0.238$ & $0.221 \pm 0.177$ & $0.091 \pm 0.13$ & $0.109 \pm$ & $0.213 \pm 0.175^{*}$ \\
\hline & & $0.154 \pm 0.1$ & $0.28 \pm 0$. & $0.232 \pm$ & $0.053 \pm 0$ & $0.109 \pm$ & $0.379 \pm 0.233$ \\
\hline \multirow{2}{*}{$\begin{array}{l}\text { Beta-1 } \\
(13.1-20 ~ H z)\end{array}$} & Schizophrenia & $0.167 \pm 0.243$ & $0.247 \pm 0.239$ & $0.215 \pm 0.192$ & $0.092 \pm 0.142$ & $0.1 \pm 0.161$ & $0.189 \pm 0.188$ \\
\hline & & $0.14 \pm 0.215$ & $0.278 \pm 0.241$ & $0.171 \pm 0.165$ & $0.066 \pm 0.158$ & $0.091 \pm 0.181$ & $0.242 \pm 0.196$ \\
\hline \multirow{2}{*}{$\begin{array}{l}\text { Beta-2 } \\
(20.1-30 \mathrm{~Hz})\end{array}$} & Schiz & $0.118 \pm 0.1$ & $0.224 \pm 0.23$ & $0.172 \pm$ & $0.069 \pm 0.1$ & $0.071 \pm 0.114$ & $0.139 \pm 0.151$ \\
\hline & & $0.12 \pm 0.183$ & $0.235 \pm 0.221$ & $0.137 \pm 0.152$ & $0.059 \pm 0.135$ & $0.061 \pm 0.111$ & $0.174 \pm 0$ \\
\hline \multirow{2}{*}{$\begin{array}{l}\text { Gamma } \\
(30.1-50 ~ H z)\end{array}$} & Schizophrenia & $0.135 \pm 0.189$ & $0.188 \pm 0.197$ & $0.144 \pm 0.114$ & $0.094 \pm 0.135$ & $0.081 \pm 0.115$ & $0.125 \pm 0.115$ \\
\hline & Control & $0.125 \pm 0.131$ & $0.252 \pm 0.215$ & $0.153 \pm 0.134$ & $0.098 \pm 0.119$ & $0.089 \pm 0.101$ & $0.179 \pm 0.146$ \\
\hline
\end{tabular}

*Significant (p-value <0.05) 
Table 3 Comparison of mean and standard deviation of Inter-hemispheric EEG coherence of schizophrenia patients with healthy controls

\begin{tabular}{|c|c|c|c|c|c|c|}
\hline \multicolumn{2}{|c|}{ Electrode Pairs } & F3-F4 & C3-C4 & P3-P4 & T3-T4 & 01-02 \\
\hline \multirow{2}{*}{$\begin{array}{l}\text { Delta } \\
(0.5-4 \text { Hz) }\end{array}$} & Schizophrenia & $0.286 \pm 0.293$ & $0.384 \pm 0.297$ & $0.288 \pm 0.29 *$ & $0.328 \pm 0.207$ & $0.797 \pm 0.169$ \\
\hline & Control & $0.274 \pm 0.286$ & $0.447 \pm 0.309$ & $0.572 \pm 0.273$ & $0.285 \pm 0.192$ & $0.705 \pm 0.168$ \\
\hline \multirow{2}{*}{$\begin{array}{l}\text { Theta } \\
\text { (4.1-8 Hz) }\end{array}$} & Schizophrenia & $0.232 \pm 0.288$ & $0.27 \pm 0.246$ & $0.202 \pm 0.231^{*}$ & $0.184 \pm 0.2$ & $0.667 \pm 0.246$ \\
\hline & Control & $0.241 \pm 0.239$ & $0.277 \pm 0.211$ & $0.408 \pm 0.258$ & $0.144 \pm 0.124$ & $0.603 \pm 0.172$ \\
\hline \multirow{2}{*}{$\begin{array}{l}\text { Alpha-1 } \\
(8.1 \text { - 10 Hz) }\end{array}$} & Schizophrenia & $0.316 \pm 0.275$ & $0.192 \pm 0.184$ & $0.182 \pm 0.181$ & $0.134 \pm 0.079$ & $0.691 \pm 0.25$ \\
\hline & Control & $0.26 \pm 0.318$ & $0.234 \pm 0.206$ & $0.284 \pm 0.237$ & $0.126 \pm 0.099$ & $0.579 \pm 0.189$ \\
\hline \multirow{2}{*}{$\begin{array}{l}\text { Alpha-2 } \\
(10.1 \text { - 13 Hz) }\end{array}$} & Schizophrenia & $0.204 \pm 0.233$ & $0.134 \pm 0.171$ & $0.148 \pm 0.169$ & $0.14 \pm 0.118$ & $0.617 \pm 0.278$ \\
\hline & Control & $0.218 \pm 0.264$ & $0.159 \pm 0.176$ & $0.195 \pm 0.213$ & $0.149 \pm 0.107$ & $0.517 \pm 0.208$ \\
\hline \multirow{2}{*}{$\begin{array}{l}\text { Beta-1 } \\
(13.1 \text { - } 20 \mathrm{~Hz})\end{array}$} & Schizophrenia & $0.158 \pm 0.219$ & $0.12 \pm 0.178$ & $0.13 \pm 0.179$ & $0.143 \pm 0.141$ & $0.585 \pm 0.281$ \\
\hline & Cor & $0.125 \pm 0.21$ & $0.116 \pm 0.183$ & $0.17 \pm 0.204$ & $0.118 \pm 0.109$ & $0.448 \pm 0.188$ \\
\hline \multirow{2}{*}{$\begin{array}{l}\text { Beta-2 } \\
(20.1 \text { - } 30 \mathrm{~Hz})\end{array}$} & Schizophrenia & $0.089 \pm 0.128$ & $0.072 \pm 0.107$ & $0.109 \pm 0.148$ & $0.109 \pm 0.097$ & $0.559 \pm 0.261$ \\
\hline & Control & $0.089 \pm 0.16$ & $0.098 \pm 0.171$ & $0.153 \pm 0.21$ & $0.09 \pm 0.058$ & $0.441 \pm 0.194$ \\
\hline \multirow{2}{*}{$\begin{array}{l}\text { Gamma } \\
(30.1-50 \mathrm{~Hz})\end{array}$} & Schizophrenia & $0.125 \pm 0.179$ & $0.11 \pm 0.142$ & $0.097 \pm 0.103^{*}$ & $0.123 \pm 0.104$ & $0.498 \pm 0.257$ \\
\hline & Control & $0.107 \pm 0.109$ & $0.135 \pm 0.161$ & $0.211 \pm 0.199$ & $0.101 \pm 0.061$ & $0.476 \pm 0.185$ \\
\hline
\end{tabular}

*Significant ( $\mathrm{p}$-value $<0.05$ )

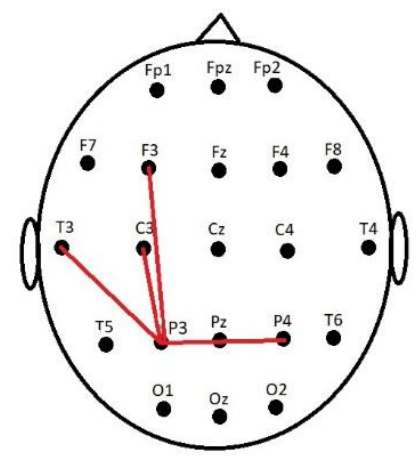

Delta band

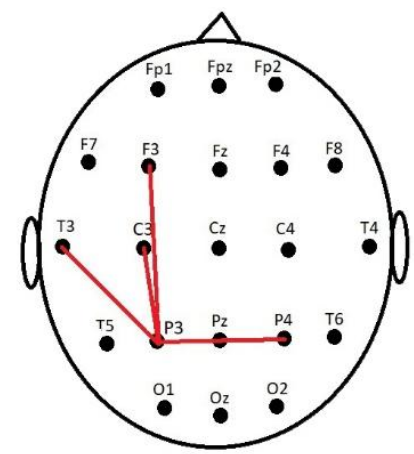

Theta band

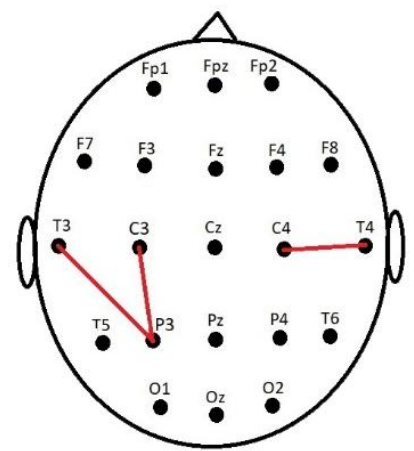

Alpha-1 \& 2 bands

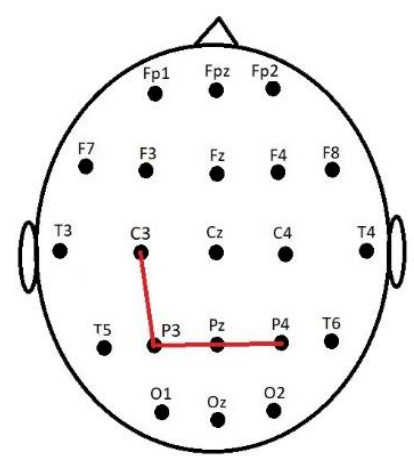

Gamma band

Figure 1 EEG head map depicting the functional connectivity using coherence between different electrode areas

\section{Discussion}

Schizophrenia is a chronic and a disabling mental disorder with a considerable impact on the psychosocial functioning and quality of life ${ }^{[32]}$. Defect in neural oscillations and their synchronization has been suggested as a pathophysiological mechanism in schizophrenia patients in recent available literature. This deranged functional connectivity in schizophrenics, was evaluated in the present study, using intra and interhemispheric EEG spectral coherence among various frequency bands.

\section{Intra-hemispheric resting EEG Coherence}

The present study showed significantly reduced left intra-hemispheric coherence in delta (C3-P3, P3-T3 and F3-P3), theta (C3-P3, P3-T3 and F3-P3), gamma (C3-P3) bands in schizophrenics as compared to healthy controls in resting state. The coherence in alpha-1 and alpha-2 bands in C3-P3 and P3-T3 electrode pairs was also significantly lower in schizophrenics as compared to healthy controls (Table 1, Figure 1). The present study also showed significantly lower right intra-hemispheric resting EEG coherence in C4-T4 electrode pair in alpha-1 and alpha-2 bands in schizophrenia patients as compared to controls (Table 2, Figure 1).

\section{Inter-hemispheric resting EEG coherence}

The interhemispheric comparison of resting EEG coherence at parietal region (P3-P4) in delta, theta and gamma bands revealed significantly lower coherence in schizophrenia patients as compared to healthy controls (Table 3, Figure 1).

Several studies have tried to assess the functional connectivity in schizophrenics and suggested reduced EEG spectral coherence in various frequency bands at different brain regions ${ }^{[33]}$. The 
reduced coherence shows the lack of brain synchronization in schizophrenia patients. John et al. (2002) also reported significantly lower interhemispheric coherence values across the central and parietal regions in the eyes closed condition and across central regions in the eyes open condition ${ }^{[34]}$. Schizophrenics have shown poor performance on cognitive task. This dysfunction and the psychopathology of schizophrenia might be attributable to the cortical hyperactivation and reduced spontaneous and induced gamma coherence [35]. The aberrant functional organization leading to poor performance of cognitive activation task in schizophrenia patients has also been linked to altered alpha band coherence ${ }^{[36]}$.

Phase lag index is another useful parameter to assess functional connectivity. EEG analysis in schizophrenia patients using phase lag index has also revealed reduced functional connectivity of beta (frontal region) and gamma bands (throughout scalp). Moreover, this dysfunctional connectivity in schizophrenics did not vary with symptoms severity or antipsychotic treatment ${ }^{[37]}$. However, the negative symptoms in schizophrenia patients have shown association with lower interhemispheric alpha coherence between hemispheres and between right parietal and frontal regions ${ }^{[38]}$.

Ray and Ram (2012) suggested both a deficit and excess in neural connections that may be attributable to a compensatory change in schizophrenics with formal thought disorder. This neural disconnection was indicated by reduced intra hemispheric coherence in schizophrenia patients with FTD and reduced interhemispheric coherence in those without FTD provides ${ }^{[39]}$. These findings might explain the variable results of EEG coherence reported in various studies done on schizophrenia patients. This could also explain the findings of the present study where a reduced intra and inter hemispheric coherence was observed in various frequency bands.

A recent study has also indicated higher intrahemispheric coherence in healthy controls as compared to schizophrenia patients in Beta-1 band ${ }^{[40]}$. Yeragani et al. (2006) also reported reduced coherence during the wake stage in patients with schizophrenia in beta as well as gamma frequency bands $^{[41]}$. An EEG spectral coherence study among cortical areas involved in the auditory information processing suggested significantly reduced coherence in upper alpha band in schizophrenics with history of auditory hallucination, as compared to healthy controls in $\mathrm{C} 3-\mathrm{C} 4, \mathrm{C} 5-\mathrm{C} 6, \mathrm{Ft} 7-\mathrm{Ft} 8$ and Cp5-Cp6 electrode pairs ${ }^{[42]}$. The reduced EEG coherence in schizophrenia patients is also a potentially heritable trait predisposing the unaffected siblings to genetic risk of schizophrenia [43].

\section{Functional dysconnectivity in left hemisphere in schizophrenia}

The brain exhibits a hemispheric asymmetry, with different function designated to different brain hemispheres. The findings of the present study indicate at a greater dysfunctional connectivity in terms of reduced intra-hemispheric EEG coherence (C3-P3, P3-T3 and F3-P3) in left hemisphere as compared to right. Previously available data also indicates at overall more left hemisphere dysfunction and overactivation ${ }^{[44]}$.

This dysfunction is also evident from a metaanalysis study of tensor imaging studies in schizophrenia patients, that suggested reduction in left frontal and left temporal deep white matter tracts. The greater number of electrode areas involved in the present study over left hemisphere might be explained by this finding, that suggests an altered brain asymmetry leading to functional disconnection in schizophrenia patients ${ }^{[45]}$.

All the above studies fully or partially support the findings of the present study, that indicate a functional disconnection over frontal, parietal and temporal regions. The available literature on functional connectivity in schizophrenia suggests mixed findings. Many studies have also reported increased coherence at rest in schizophrenia patients in various frequency bands that contrasts with findings of the present study but suggest another possible mechanism underlying impaired inter and intra-hemispheric functional connectivity ${ }^{[46]-[49]}$. 


\section{Conclusion}

The schizophrenia patients exhibit functional dysconnectivity in frontal, central, parietal and temporal regions. This impairment in connectivity was greater over left hemisphere, that might account for the impaired thought process, logical reasoning, perception and language in schizophrenia patients.

\section{Limitations of the Present Study}

This study did not take into account the association between symptoms of schizophrenia and coherence. A large-scale study considering symptoms of schizophrenia in future is needed for a better understanding of the underlying defect in functional connectivity.

\section{References}

1. Kuperberg G, Heckers S. Schizophrenia and cognitive function. Curr Opin Neurobiol. 2000;10(2):205-10.

2. Ventura J, Hellemann GS, Thames AD, Koellner V, Nuechterlein KH. Symptoms as mediators of the relationship between neurocognition and functional outcome in schizophrenia: a meta-analysis. Schizophr Res. 2009;113(2-3):189-99.

3. Reichenberg A, Caspi A, Harrington $\mathrm{H}$, Houts R, Keefe RS, Murray RM, et al. Static and dynamic cognitive deficits in childhood preceding adult schizophrenia: a 30-year study. Am J Psychiatry. 2010;167(2):160-9.

4. Barch DM, Cohen R, Csernansky J. Altered cognitive development in the siblings of individuals with schizophrenia. Clin Psychol Sci. 2014;2(2):138-51.

5. Friston KJ. The disconnection hypothesis. Schizophr Res 1998;30:115-25.

6. Ribolsi M, Koch G, Magni V, Di Lorenzo G, Rubino IA, Siracusano A, et al. Abnormal brain lateralization and connectivity in schizophrenia. Rev Neurosci 2009;20:6170.

7. Schmitt A, Hasan A, Gruber O, Falkai P. Schizophrenia as a disorder of disconnectivity. Eur Arch Psychiatry Clin Neurosci 2011;261(Suppl 2):S150-4.

8. Stephan KE, Baldeweg T, Friston KJ. Synaptic plasticity and dysconnection in schizophrenia. Biol Psychiatry 2006;59:929_ 39.

9. Di Lorenzo G, Daverio A, Ferrentino F, Santarnecchi E, Ciabattini F, Monaco L, et al. Altered resting-state EEG source functional connectivity in schizophrenia: the effect of illness duration. Front Hum Neurosci 2015;9:234.

10. Foucher JR, Vidailhet P, Chanraud S, Gounot D, Grucker D, Pins D, et al. Functional integration in schizophrenia: too little or too much? Preliminary results on fMRI data. Neuroimage 2005;26:374-88.

11. Roiser JP, Wigton R, Kilner JM, Mendez MA, Hon N, Friston KJ, et al. Dysconnectivity in the frontoparietal attention network in schizophrenia. Front Psychiatry 2013;4:176.

12. Whitfield-Gabrieli S, Thermenos HW, Milanovic S, Tsuang MT, Faraone SV, McCarley RW, et al. Hyperactivity and hyperconnectivity of the default network in schizophrenia and in first-degree relatives of persons with schizophrenia. Proc Natl Acad Sci USA 2009;106:1279-84.

13. Barry RJ, Clarke AR, Johnstone SJ. A review of electrophysiology in attentiondeficit / hyperactivity disorder: I. Qualitative and quantitative electroencephalography. Clinical Neurophysiology. 2003;14:171-83.

14. Thibodeau R, Jorgensen RS, Kim S. Depression, anxiety, and resting frontal EEG asymmetry: a metanalytic review. Journal of abnormal psychology. 2006; 115(4):715-29.

15. Bowyer M. S. Coherence a measure of the brain networks: past and present. Bowyer Neuropsychiatric Electrophysiology (2016) 2:1.

16. Northoff G, Heinel A, de Greck M, Bermpohl F, Dobrowolny H, Panksepp J. Self-referential processing in our brain-a 
meta-analysis of imaging studies on the self. NeuroImage 2006;31(1):440-57.

17. Van der Meer L, Costafreda S, Aleman A, David AS. Self-refelction and the brain: a theoretical review and meta-analysis of neuroimaging studies with implications for schizophrenia. Neurosci Biobehav Rev 2010;34(6):935-46.

18. Fingelkurts AA, Fingelkurts AA. Persistent operational synchrony within brain defaultmode network and self-processing operations in healthy subjects. Brain Cogn 2011; 75(2)79-90.

19. Kim HA. Dual subsystem model of the brain's default network: self-referential processing, memory retrieval processes and autobiographical memory retrieval. Neuroimage 2012;61(4):966-77.

20. Svoboda E, Mckinnon MC, Levine B. The functional neuroanatomy of autobiographical memory: a meta-analysis. Neuropsychologia 2006;44(12):2189-208.

21. Iqbal Z, Birchwood M, Hemsley D, Jackson C, Morris E. Autobiographical memory and post-psychotic depression in first episode psychosis. Br J Clin Psychol 2004;43:97104.

22. Fisher M, McCoy K, Poole JH, Vinogradov S. Self and other in schizophrenia: a cognitive neuroscience perspective. Am J Psychiatry 2008;165(11):1465-72.

23. Holt DJ, Cassidy BS, Andrews-Hanna JR, Lee SM, Coombs G, Goff DC, et al. An anterior to posterior shift in midline cortical activity in schizophrenia during selfreflection. Biol Psychiatry 2011; 69(5): 41523.

24. Greicius MD, Krasnow B, Reiss AL, Menon V. Functional connectivity in the resting brain: a network analysis of the default mode hypothesis: Proc Natl Acad Sci USA 2003;2003(1)253-8.

25. Li SJ, Li Z, Wu G, Zhang M J, Franczak M, Antuono PG. Alzheimer disease: evaluation of a functional MR imaging index as a marker. Radiology 2002;225(1)253-9.

26. Gusnard DA, RAichle ME. Searching for a baseline: functional imaging and the resting human brain. Nat Rev Neurosci 2001; 2:685-94.

27. Hlinka J, Alexakis C, Diukova A, Liddle PF, Auer DP. Slow EEG pattern predicts reduced intrinsic functional connectivity in the default mode network: and inter subject analysis. NeuroImage 2010;53(1):239-46.

28. Takahashi T, Goto T, Nobukawa S, Tanaka Y, Kikuchi M, Higashima M, Wadab Y. Abnormal functional connectivity of highfrequency rhythms in drug-naïve schizophrenia. Clinical Neurophysiology 129 (2018) 222-231.

29. Jalili M, Lavoie S, Deppen P, Meuli R, Do KQ, et al (2007) Dysconnection Topography in Schizophrenia Revealed with State-Space Analysis of EEG. PLoS ONE 2(10): e1059.

30. Morrison-Stewart (a2), E. Helmes (a3) and L. Cortese (a4). EEG coherence and syndromes in schizophrenia. Volume 170, Issue 5 May 1997, pp. 411-415.

31. Jasper HH. The international "10-20" system of the International Federation. Electroencephalography and Clinical Neurophysiology. 1958;10:371-5.Jasper HH. The international "10-20" system of the International Federation. Electroencephalography and Clinical Neurophysiology. 1958;10:371-5.

32. Kuperberg G, Heckers S. Schizophrenia and cognitive function. CurrOpinNeurobiol. 2000;10(2):205-10.

33. Morrison-Stewart SL, Velikonja D, Corning WC, Williamson P. Aberrant interhemispheric alpha coherence on electroencephalography in schizophrenic patients during activation tasks. Psychol Med. 1996 May;26(3):605-12.

34. John PJ, Khanna S, Pradhan N \&Mukundan CR. EEG alpha coherence and psychopathological dimensions of 
Schizophrenia. Indian Journal of Psychiatry. 2002;44(2):97-107.

35. Bandyopadhyaya D, Nizamie SH, Pradhan N, Bandyopadhyaya A. Spontaneous gamma coherence as a possible trait marker of schizophrenia-An explorative study. Asian J Psychiatr. 2011 Sep;4(3):172-7.

36. Morrison-Stewart SL, Williamson PC, Corning WC, Kutcher SP, Merskey $\mathrm{H}$. Coherence on electroencephalography and aberrant functional organisation of the brain in schizophrenic patients during activation tasks. Br J Psychiatry. 1991 Nov;159:63644.

37. Takahashi T, Goto T, Nobukawa S, Tanaka Y, Kikuchi M, Higashima M, Wadab Y. Abnormal functional connectivity of highfrequency rhythms in drug-naïve schizophrenia. Clinical Neurophysiology. 2018; (129): 222-231.

38. Merrin EL, Floyd TC. Negative symptoms and EEG alpha in schizophrenia: a replication. Schizophr Res. 1996 May;19(23):151-61.

39. Ray D, Ram D. Electrophysiological examination of Formal Thought Disorder in Schizophrenia. Asian Journal of Psychiatry. 2012;5(4):327-338.

40. Kam JW, Bolbecker AR, O'Donnell BF, Hetrick WP, Brenner CA. Resting state EEG power and coherence abnormalities in bipolar disorder and schizophrenia. J Psychiatr Res. 2013 Dec;47(12):1893-901.

41. Yeragani VK, Cashmere D, Miewald J, Tancer M, Keshavan MS. Decreased coherence in higher frequency ranges (beta and gamma) between central and frontal EEG in patients with schizophrenia: A preliminary report. Psychiatry research. 2006; 141(1):53-60.

42. Henshall KR, Sergejew AA, Rance G, McKay CM, Copolov DL. Interhemispheric
EEG coherence is reduced in auditory cortical regions in schizophrenia patients with auditory hallucinations. International Journal of Psychophysiology. Volume 89, Issue 1, July 2013, Pages 63-7. doi:10.1016/ j.ijpsycho.2013.05.005.

43. Winterer G, Egan MF, Rädler T, Hyde T, Coppola R, Weinberger DR. An association between reduced interhemispheric EEG coherence in the temporal lobe and genetic risk for schizophrenia. Schizophr Res. 2001 Apr 15;49(1-2):129-43.

44. Gur, Raquel E. Left hemisphere dysfunction and left hemisphere overactivation in schizophrenia. Journal of Abnormal Psychology, 87(2), Apr 1978, 226-238.

45. Ellison-Wright I, Bullmore E. Meta-analysis of diffusion tensor imaging studies in schizophrenia. 2009; Schizophr. Res. 108, 3-10. doi:10.1016/j.schres.2008. 11.021

46. Merrin EL, Floyd TC, Fein G. EEG coherence in unmedicated schizophrenic patients. Biol Psychiatry. 1989;25(1):60-66.

47. Nagase Y, Okubo Y, Matsuura M, Kojima $\mathrm{T}$, Toru M. EEG coherence in unmedicated schizophrenicpatients: topographical study of predominantly never medicated cases. Biological psychiatry.1992; 32(11):1028-34. 48. Mann K, Maier W, Franke P, Röschke J, Gänsicke M. Intra- and interhemispheric electroencephalogram coherence in siblings discordant for schizophrenia and healthy volunteers. Biological psychiatry. 1997; 42(8):655-63.

49. Wada Y, Nanbu Y, Kikuchi M, Koshino Y, Hashimoto T. Aberrant functional organization inschizophrenia: analysis of EEG coherence during rest and photic stimulation in drug-naïve patients. Neuropsychobiology. 1998 Jan; 38(2):63-9. 